\title{
The Feasibility Study of Ammonia Absorption Refrigeration System in Ship Application
}

\author{
Zhaoqiang $\mathrm{LI}^{1, \mathrm{a}}$ and Haijun Yang ${ }^{2, \mathrm{~b},{ }^{*}}$ \\ ${ }^{12}$ Binzhou Polytechnic, Binzhou 256600, China \\ a474637466@qq.com, b176816963@qq.com
}

\begin{abstract}
Keywords: Host cylinder jacket cooling water; Ammonia absorption; Compression combined cycle system; Feasibility study
\end{abstract}

\begin{abstract}
The heat more than half of ship diesel engine exhaust gas and cooling water to the outside world, caused great waste of energy, on the other hand, the ship everyday want to consume large amounts of electricity to maintain the normal operation of the refrigerator and air conditioning system of the ship. Us from reducing air pollution and energy consumption, the perspective of reducing operating costs, to a round of refrigeration system as an example, explores the host cylinder liner cooling water as the generator heat source of ammonia absorption refrigeration system, the feasibility of the application on the ship, the key to solve the host cylinder liner cooling water heat source on the host when parking the discontinuous problems and adding ammonia compressor system in order to solve the host cylinder liner cooling water temperature is lower than the traditional heat source temperature needed by the generator. Through the design practice, it makes good use of the abandoned heat source of ship, improves the thermal efficiency of Marine diesel engine, reduces the consumption of electric energy, and improves the economy of ship operation.
\end{abstract}

\section{The Research Background}

At present, most ships use diesel engines as the main propulsion system, the most important factor is that the diesel engine has the highest thermal efficiency in all the engines. But even so, the diesel engine's thermal efficiency is only 40 to 45 percent, and the rest of the heat is taken away by waste gas and cooling water. According to statistics, about $30 \%$ of the heat is taken away from the exhaust gas, and the heat from the cooling water of the diesel engine is also up to $20 \%$, resulting in a huge waste of energy. With the rising of international oil price and the increasing progress of energy saving and emission reduction technology, how to improve the thermal efficiency of diesel engine is the direction we are exploring. At present is the most important measures to improve thermal efficiency of diesel engine will be fully utilized, this part of energy such as exhaust gas turbo diesel engine technology and the application of exhaust gas boiler, makes the diesel engine exhaust gas residual heat has made full use of, but because of its low heat source grade diesel engine cooling water, technology is difficult, not fully development.

Ocean-going vessels, especially ocean-going fishing vessels, require refrigeration equipment to refrigerate food and cargo, and poor Marine climate conditions require air-conditioning systems to improve the working environment. At present, the main refrigeration method is the piston type refrigeration compressor, which consumes high grade electrical energy. And if the absorption refrigeration technology, the heat energy can make full use of diesel engine exhaust gas and cooling water away as a source of power, can not only improve the thermal efficiency of diesel engine, and reduce the electricity consumption, but also can solve the problem of traditional refrigeration system of refrigerant replacement.

\section{Research Status}

Absorption refrigeration technology at present there are mainly of two kinds of ammonia absorption refrigeration and liar absorption refrigeration, but as a result of lithium bromide easily crystallized, for metal has the strong corrosion as well as the equipment is expensive, initial investment is high, and can 
only be applied to more than $0{ }^{\circ} \mathrm{C}$ refrigeration and other reasons, not suitable for application in the ship. Counterpart, ammonia refrigeration technology, although need to furnish distillation, but its theoretical refrigeration range 0 to $60{ }^{\circ} \mathrm{C}$, and for its pungent odor, reveal the advantages of easy to find, more suitable for Marine. So the current research direction is the application of ammonia refrigeration system on ships. Chen linmin et al of southeast university theoretically calculated the ammonia refrigeration system of the exhaust gas of the fishing vessel diesel engine as a heat source, and put forward some Suggestions for improvement. In hunan province, the company has developed a prototype of the Marine engine exhaust adsorption ice machine of the fishing boat, and realized the marketization. Wang shugang of Shanghai jiaotong university focuses on the application prospect of the steam boiler of ship exhaust heat pipe as the absorption refrigeration system of heat source. Overall, absorption refrigeration technology at present mainly in diesel engine exhaust heat source as the main research object, and because of the diesel engine cooling water temperature is relatively low, the application is difficult, haven't got enough attention, this article namely take a wheel as the research object, explore to host cooling water as heat source, discusses the application of ammonia absorption refrigeration technology in ship.

\section{Feasibility Study on Cooling Water - Ammonia Absorption Refrigeration}

\section{Calculation of heat source load}

The application of refrigeration system in ship is mainly cold storage and air conditioning. There are two piston type refrigeration compressors in a cold bank, and R22 is used as refrigerant. Fish library setting temperature of $14{ }^{\circ} \mathrm{C}$ below zero to minus $18{ }^{\circ} \mathrm{C}$, vegetable base set temperature is $2{ }^{\circ} \mathrm{C}$ to $6{ }^{\circ} \mathrm{C}$, food library set temperature of $14{ }^{\circ} \mathrm{C}$ to $16{ }^{\circ} \mathrm{C}$. The maximum operating power during operation is $19.3 \mathrm{KW}$. Refrigeration air conditioning USES two screw compressor, R22 refrigerant, single machine operating power $23.7 \mathrm{KW}$, summer operation maximum design power $27.9 \mathrm{KW}$.

In cold storage and air-conditioning are calculated according to the maximum operating power, its operating power is $47.2 \mathrm{KW}$, the theory of the refrigeration compressor refrigeration coefficient between 2.55 , we with 3.25 meter, vessels is the maximum heat load $\mathrm{QM}=\mathrm{P} * \mathrm{COP}=47.2 * 47.2=$ 153.4 KW. And the ship USES the central cooling system, we host cylinder liner cooling water as heat source, based mainly on two aspects: one is the host cylinder liner cooling water to fresh water, the water quality is better, less corrosion, on the other hand is the cylinder liner cooling water temperature is much higher than external cooling with water. The host cylinder liner cooling water outlet temperature is $90{ }^{\circ} \mathrm{C}$, assuming that ammonia absorption refrigeration system generator inlet temperature is $90{ }^{\circ} \mathrm{C}$, set the outlet temperature as $80{ }^{\circ} \mathrm{C}$, cooling water flow rate is about $50 \mathrm{~m} 3 / \mathrm{h}$.

$$
\mathrm{Q}_{\mathrm{w}}=\mathrm{GC}(\mathrm{t} 2-\mathrm{t} 1)=50 \times 1000 \mathrm{~kg} / \mathrm{m}^{3} \times 4.2 \times 10^{3} \times 10=21 \times 10^{5} \mathrm{KJ} / \mathrm{h}=583 \mathrm{KW}
$$

Type:

Qw: the energy provided by the jacket cooling water.

$\mathrm{G}$ : the mass flow of the cooling water, the cooling water density is calculated by $1 \mathrm{~kg} / \mathrm{L}$.

$\mathrm{C}$ : cooling water heat to $4.2 \mathrm{KJ} /\left(\mathrm{KG}^{*}{ }^{\circ} \mathrm{C}\right)$

Considering that the refrigerating coefficient of absorption refrigeration is generally lower, the value is 0.6 , and the cooling capacity of the cooling water of diesel cylinder jacket is theoretically calculated.

$$
\mathrm{Q}_{1}=\mathrm{Q}_{\mathrm{w}} \times 0.6=583 \times 0.6=350 \mathrm{KW}
$$

From this analysis, it can be seen that the thermal load $(350 \mathrm{KW})$ provided by the cooling water of the cylinder jacket is far greater than the heat load required by the ship's refrigeration system (153.4KW). Make the reform plan theoretically feasible.

System design scheme.

In the design scheme, it is necessary to solve the following two problems in the ammonia absorption refrigeration system with the host cylinder jacket cooling water as the heat source.

(1) The premise condition of providing heat source for the cooling water of the main engine cylinder is that the host should operate normally, and how to solve the heat source problem of the ship berth and the low load navigation;

(2) In a single stage ammonia absorption refrigeration system, generator are required to provide heat 
source temperature shall not be less than $152.8{ }^{\circ} \mathrm{C}$. [6] obviously, this temperature is far greater than the heat source temperature provided by the jacket cooling water.

First, in order to solve the problem of host heat source is not stable, we will be introduced to the power of diesel engine cylinder liner cooling water in the system, at the same time will be introduced to the boiler steam system of pipeline system, the lack of cylinder liner cooling water heat source, use steam for heating jacket water, so that when needed for the generator to provide additional heat source. Second, the need for generator of high temperature, there are two solutions, one is using high grade diesel engine exhaust gas residual heat to provide heat source, but clearly this is not this article discusses the direction of the another solution is to use an ammonia absorption/joint compression refrigeration cycle system, the system can significantly reduce the required high temperature generator, the study found that if to set the compression ratio is 5.0, evaporating temperature in evaporator set to minus 20 degrees Celsius, the required heat source temperature of the generator can be reduced to 80 degrees Celsius.

The detailed system plan is as shown in the figure below:

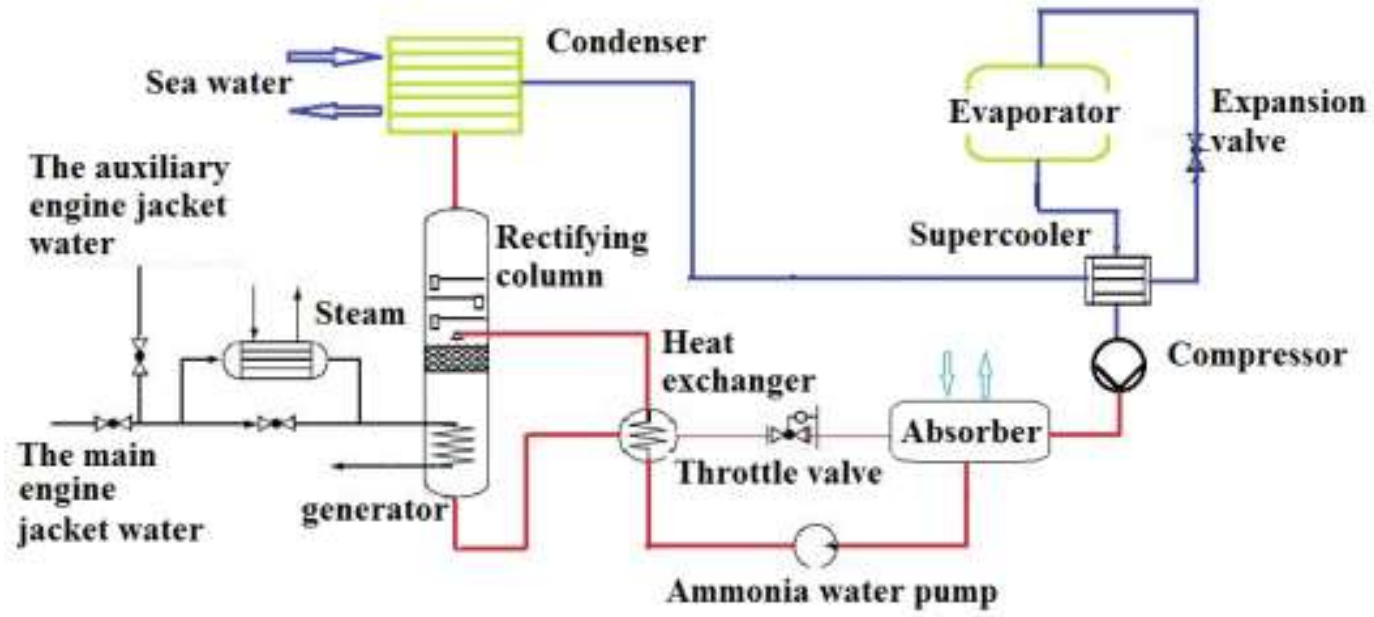

The heat source of the generator is mainly provided by the cooling water of the main cylinder jacket. When stopping, provided by the deputy machine cylinder liner cooling water heat source, considering the ship characteristics of cold storage in heat preservation phase heat load is small, the calculation, vice machine can meet the needs of the cooling jacket cooling water heat load, but add air conditioning refrigeration, refrigeration capacity may be insufficient. So we add a steam heating system, heating of cylinder liner cooling water increase refrigeration capacity, and for the steam source, we design a set of power generation machine flue gas waste heat boiler, through practice, gas production can meet the needs of the refrigeration. In order to reduce the occupancy of the tank, we designed and manufactured the generator and the rectifier, reducing the pipe loss and reducing the volume. In order to reduce the heat source required by the generator, we installed an ammonia refrigeration compressor between the cooler and the absorb-er to improve the ammonia and ammonia concentration. Because ammonia refrigeration compressor compression is low, energy consumption is less. The design and practice of in cylinder liner cooling water outlet temperature about $90{ }^{\circ} \mathrm{C}$, can meet the demand of generator to work.

\section{Economic Analysis}

Ammonia absorption/compression refrigeration cycle system mainly USES the host cooling water waste heat as a source of power, in addition to the ammonia compressor and the circulating pump, fan, basically do not need to consume energy, reduce the power load of the vessel, improve the economic benefit of the ship operations. In this round, for example, for the traditional compression refrigeration, in order to maintain the cold storage temperature requirements, daily consumption of electrical energy at about 45 degrees or so, if the refrigerator door open more frequent or more new food, the outside heat load is higher, the power consumption is bigger, considering that most of the refrigerator working state is in a state of constant temperature, we can be calculated by 60 degrees every day electricity, the annual electricity consumption is $365 \times 60=21900$ degrees. For the air-conditioning system, it is found that the 
single-stage operation power of the compressor is $8 \mathrm{KW}$, which is calculated by working 12 hours per day, and the energy consumed is 96 degrees. Assuming the air conditioning system works for 5 months each year, the energy consumed is $5 * 30 * 96=14,400$. The Marine refrigeration system consumes 36300 kilowatt-hours of electricity per year. Since the electric power of the ship is supplied by the Marine power generation diesel engine, it has low efficiency and high operating cost. Based on the calculation of the low calorific value $40780 \mathrm{KJ} / \mathrm{KG}$ of Marine heavy oil, considering the low efficiency of Marine diesel power generation, the calculation formula of oil consumption per year in the Marine refrigeration system is calculated as follows:

$$
36300 \times 3600 \mathrm{KJ}=\mathrm{M} * 0.4 * 40780 \mathrm{KJ} / \mathrm{kg}
$$

The calculation shows that $\mathrm{M}=8011 \mathrm{~kg}$, that is, the compression refrigeration system of this wheel consumes about 8 tons of heavy oil every year. The operating cost of the system is about 40,000 yuan per year based on the current market price of heavy oil at 5,135 yuan/ton. With ammonia absorption refrigeration, this part of operating costs can be saved every year, assuming that the initial installation cost of the equipment is about 100,000 yuan, and the cost can be recovered in 2.5 years.

\section{Conclusion}

The ammonia absorption refrigeration equipment USES the waste energy of the ship as the heat source and improves the efficiency of the diesel engine. But ammonia absorption refrigeration system also has its inherent drawbacks, such as large size, large ammonia leakage damage to human body, low cooling efficiency shortcomings, with the further study of the refrigeration system, believe that can get better solve all these problems. In this paper, the feasibility of the ammonia absorption refrigeration system based on the cooling water of the host cylinder is discussed in this paper.

\section{References}

[1]Shen Bo,Pan Xinxiang,Wang Weiwei.Feasibility of Absorption Refrigeration Air Conditioner Powered by West Heat [J].NAVIGATION OF CHINA,2012,35(4):33-36.

[2]Chen Linmin,Chen Yaping,Tian Ying.Analysis of residual heat utilization of water absorption refrigeration system in the tail gas of fishing boats [J].Energy Research\&Utilization,2008,1:37-40.

[3]Zhao Zongchang,Zhang Xiaodong.Thermal performance analysis of ammonia absorption compression combined refrigeration cycle driven by low temperature[J].CHEMICAL INDUSTRY AND ENGINEERING PROGRESS,2009,28:459-462. 